\title{
Spread the Voice! Digital Social Platforms as Conveyors of Innovation of Cultural Heritage in Europe
}

\author{
Mauro Baioni, Federico Ceschel *, Paola Demartini (D, Lucia Marchegiani (D, Michela Marchiori and Flavia Marucci \\ Department of Business Economics, Roma Tre University, 00145 Rome, Italy; mauro.baioni@uniroma3.it (M.B.); \\ paola.demartini@uniroma3.it (P.D.); lucia.marchegiani@uniroma3.it (L.M.); \\ michela.marchiori@uniroma3.it (M.M.); flavia.marucci@uniroma3.it (F.M.) \\ * Correspondence: federico.ceschel@uniroma3.it; Tel.: +39-3495423763
}

Citation: Baioni, M.; Ceschel, F.; Demartini, P.; Marchegiani, L.; Marchiori, M.; Marucci, F. Spread the Voice! Digital Social Platforms as Conveyors of Innovation of Cultural Heritage in Europe. Sustainability 2021, 13, 12455. https://doi.org/ $10.3390 /$ su132212455

Academic Editor: John Carman

Received: 14 October 2021

Accepted: 8 November 2021

Published: 11 November 2021

Publisher's Note: MDPI stays neutral with regard to jurisdictional claims in published maps and institutional affiliations.

Copyright: (C) 2021 by the authors. Licensee MDPI, Basel, Switzerland. This article is an open access article distributed under the terms and conditions of the Creative Commons Attribution (CC BY) license (https:// creativecommons.org/licenses/by/ $4.0 /)$.

\begin{abstract}
Digital social platforms (DSPs) are increasingly used to boost participation while giving a space for collaboration to wider audiences and marginalized groups of stakeholders. Considering that in the cultural heritage $(\mathrm{CH})$ sector they are used as a possible booster of stakeholders' participation and to foster innovation in practices related to $\mathrm{CH}$ management, the object of this study is to assess the stakeholder engagement strategies adopted by DSPs for $\mathrm{CH}$ from a network engagement perspective. The study takes stock of the main DSPs for $\mathrm{CH}$ in Europe and analyzes them through four key dimensions that distinguish different stakeholder engagement strategies (diffusion, accessibility, interactivity, and influence) to identify the alternative approaches to sustainable development based on social innovations adopted via these platforms. Following an exploratory approach, the research also delves into a specific case study (SoPHIA DSP), to deepen the understanding of if and how DSPs foster knowledge sharing among the different actors involved in a cultural project. Ultimately, this research provides a snapshot of the state of the arts on the literature and practices on DSPs, and outlines directions for future research, requesting for a longitudinal perspective to the framework and a vertical focus for consolidating the engagement strategies variables.
\end{abstract}

Keywords: cultural heritage; digital social platforms; stakeholder network engagement; digital culture; heritage community; participation

\section{Introduction}

Today, in any business context, public or private, the advantages of more directly involved stakeholders (customers, clients, suppliers, or partners) using digital platforms and creating value by identifying their needs and providing effective solutions are widely recognized $[1,2]$.

The cultural and creative industries make no exception. Not only have digital culture and digital arts proliferated, but digital technologies are also instrumental in fostering broader participation, innovation, and a more inclusive governance of cultural initiatives. Instead of relying solely on their resources, organizations can involve external parties in idea generation, collaborative experimentation, and problem-solving processes [3]. The literature has shown that learning processes allow the cultural organization to "develop the capability to obtain, identify, integrate, and utilize acquired knowledge to improve internal skills and adapt to external environmental changes" [4] (p. 258). Moreover, European cultural policies have recognized the importance of ensuring audience access and participation for some time [5]. The debate on participating in cultural heritage is lively and several definitions are provided [6]. In this context, the digitization processes should allow wider participation in culture, not only of practitioners and cultural professionals, but also of non-professionals in cultural programs and policies [7].

Digital social platforms (DSPs) are sought to boost participation and to give space for collaboration to wider audiences and marginalized groups of stakeholders. Adopting open innovation tools in the cultural sector present multiple positive benefits, including 
improved awareness of social problems, more effective practices based on broad citizen experience, and increased trust between private/public organizations and citizens [8-10]. Nevertheless, the extent to which these opportunities are transformed into positive outcomes is still under-investigated. Moreover, an interesting debate is rising on how to pass from virtual reality to actual reality, considering information as "materialized rationality", and digital platforms as artifacts that spatial-temporal structures to store, display, integrate, code, and decode information in the different natural systems and processes [11].

Looking at the relationship between the different actors involved in this innovative and creative process, research on stakeholder theory has increasingly conceptualized the facets of the relationship between a single organization and its stakeholders as a network [12] overcoming the dyadic level of analysis [13]. Furthermore, research on engagement has grown in significance and impact in recent years, highlighting both its theoretical and practical relevance $[14,15]$. If organizations understand the effect of multiple, parallel engagement contexts within which actors are connected, they can work to create improved engagement contexts, including through platform facilitation and/or other support mechanisms, thus resulting in engagement-conducive (and disengagementreductive) institutions and institutional arrangements. DSPs are instrumental to this virtuous process, as they can nurture network effects and increase the marginal utility of network participants [16]. These positive effects should reinforce the incentives to participate in the platform, thus activating a virtuous cycle of participation.

From a different perspective, creating a DSP boosts the ability of cultural organizations to reach out to their stakeholders, while also closely monitoring their interactions. However, assessing the cultural organization's stakeholder networks, especially measuring the level of engagement that these networks stimulate, is still under-investigated [17].

Okazaki and colleagues [17] established a theoretical framework to understand, capture, and measure stakeholder network engagement (SNE). By analyzing the literature on marketing, management, and communication, they identified four key dimensions that distinguish different stakeholder engagement strategies, namely, diffusion, accessibility, interactivity, and influence. Moreover, they proposed an approach to assess an organization's SNE index. Based on this, considering the DSPs for cultural heritage $(\mathrm{CH})$ as a possible booster of stakeholders' participation and innovation in practices related to cultural heritage management, this research assesses the stakeholder engagement strategies by conceptually examining these relationships from a network engagement perspective.

First, we identify and classify the main DSPs for CH in Europe and we fully examine the online discourse promoted by them.

Secondly, we analyze these DSPs adopting the SNE approach through the four key dimensions that distinguish different stakeholder engagement strategies (diffusion, accessibility, interactivity, and influence) [17].

Furthermore, we use the same theoretical framework of analysis to critically and in depth evaluate a specific and innovative single case study, through an action research approach, and focusing on the SoPHIA project (Social Platform for Holistic Heritage Impact Assessment), a two-year European project under the H2020 program. The project is coordinated by Roma Tre University (UNIROMA3), Italy, and brings together a diverse Consortium of European organizations: Interarts Foundation for International Cultural Cooperation (INTERARTS), Spain; European Museum Academy (EMA), The Netherlands; Institute of Cultural Policy and Cultural Management (EDUCULT), Austria; National Technical University of Athens (NTUA), Greece; Dun Laoghaire Institute of Art, Design \& Technology (IADT), Ireland; and the Institute for Development and International Relations (IRMO), Croatia. SoPHIA DSP is the latest social platform on $\mathrm{CH}$, and it is aimed at supporting the collaboration of the SoPHIA community of practice towards the development and implementation of the project activities. Adapted to the specific needs of the project, the consortium chose the eXo software that offers possibilities for communication, collaboration, engagement, and knowledge sharing through an "independent digital workplace solution". 
Empirical research [18-21] on DSPs influence participation, levels of engagement, or awareness is limited. Thus, we have chosen the exploratory approach as an appropriate way to establish the field in the early stages of an emerging topic [22]. The exploratory approach and the action research method were rigorously validated by triangulating the information collected through the SNE analysis with the evidence of perceptions of the SoPHIA DSP main users. This prevented any subjective biases over the results obtained on SoPHIA DSP.

Focusing on how dialogue, participation, and collaboration develop across digital platforms in the specific domain of cultural heritage practices, we discuss how collective knowledge components can contribute to creating value for individuals and society. Our research question is formulated as follows:

RQ: In the cultural heritage sector, are DSPs able to stimulate dialogue and interaction between the stakeholders as well as increase the level of stakeholder network engagement (SNE)?

\section{Theoretical Background}

Innovative DSPs foster interaction and knowledge dissemination supporting the design of cultural and tourism policies and strategies $[23,24]$. To this end, their role goes far beyond the mere technical tool. They expand the role of the heritage community in terms of contributors to $\mathrm{CH}$ preservation and identification of the artifacts to preserve [25-27], by engaging and including heritage practitioners and participants in the knowledge sharing.

The Council of Europe's Framework Convention on the Value of Cultural Heritage for Society (so-called the Faro Convention) has introduced the concept of heritage communities, defined as "a group of people who attribute value to specific aspects of cultural heritage, and who wish, in the framework of public action, to support them and pass them on to future generations" (Council of Europe 2005, art. 2b).

In this sense, the definition of heritage communities is strongly assimilable to the concept of stakeholder network, described by Svendsen and Laberge [28] as "a web of groups, organizations, and/or individuals who come together to address a complex and shared cross-boundary problem, issue or opportunity" [28] (p. 92).

In turn, the concept of community is closely linked with the notions of access, participation, and representation. Communities play a fundamental role in the valorization of heritage, since-through participatory processes-they consciously own the values that are connected to it, redefining them. In fact, the concept of "value" is a socially constructed concept that changes over time and that depends on historical, social, and cultural factors.

For this reason, it becomes crucial to explore how to measure and evaluate the strategies adopted to foster stakeholder engagement, defined as "practices the organization undertakes to involve stakeholders in a positive manner in organizational activities" [29] (p. 315). To do this, we adopted the methodological approach proposed by Okazaki and colleagues [17], adapting it to the cultural heritage context. In this approach, the stakeholder network engagement (SNE) is composed of four theoretical dimensions-diffusion, accessibility, interactivity, and influence-and these dimensions are essential to allow co-creation of value by stakeholders within that network. Here follows a definition of each dimension:

Diffusion is linked to the intent of the content sender of promoting or restricting content distribution to actors that might not be part of the original targeted audience [30].

Accessibility refers to the stakeholders' ability or inability to enjoy content based on the organization's potential to reach them [31,32].

Interactivity measures how much the content invites the audience to further exchange or co-produce additional content together with the organization and its network [33].

Influence represents the persuasive ability of an organization or individual actors to exchange, further distribute, and interact with their contents and key message [34]. 


\section{Methodology}

In order to analyze DSPs as viable means to convey participation towards knowledge sharing in the assessment of cultural interventions, the authors adopted a qualitative approach in both phases of the study, which are presented below.

In the first phase, we selected several DSPs, and we analyzed the online discourse that unfolds over them. As a selection criterion, we first included in our study the institutionally supported DSPs that have received funding from the EU. Moreover, recognizing the call for active participation fostered from the Faro Convention onwards, we also included DSPs that are not EU-backed, but have gained general recognition in the debate on innovative impact assessment of cultural interventions. These DSPs have been selected through a non-probability referral sampling technique.

As a study protocol, we conducted an in-depth analysis of the text to detect the evolution of the online discourse that has deployed over time, namely:

(a) Who participated in the online discourse?

(b) What has been the content of the online discourse?

In the second phase of the study, each author independently assessed the SNE of all DSPs identified as well as of the SoPHIA DSP using the framework proposed by Okazaki and colleagues [17].

Consistently with the exploratory approach, we adopted a method based on action research to complement the previous analysis of the selected DSPs with primary data on the SoPHIA DSP as an in-depth case study [35] with unique circumstances. In fact, all the authors are directly involved with the SoPHIA DSP, have participated in its design, and continue to contribute to its management and growth. This provides deep knowledge on the functioning mechanisms as well as on the criticalities encountered. Furthermore, SoPHIA is chronologically the last DSP to have been activated in the specific field of $\mathrm{CH}$ (July 2020), as well as being implemented during the period following the spread of COVID-19. This has given a particular impetus to the adoption of digital tools to replace traditional methods of dialogue and participation.

To validate the obtained results, the research group compared the different assessments and formulated, after discussing them, synthetic results based on three levels (high, medium, and low) for each dimension of analysis. Since the theoretical framework used is not specific for the $\mathrm{CH}$ domain, we have adapted it to our specific field of study by elaborating specific measures or metrics for each dimension of SNE.

For example, in the case of diffusion, we assessed whether the DSPs encourages the dissemination of messages through mailing lists, newsletters, or the use of social media (low level: no clear content diffusion strategy emerges, no use of mailing lists or newsletters, and no use of social media; medium level: a content diffusion strategy emerges, use of mailing lists or newsletters, and a limited use of social media; and high level: clear and evident content diffusion strategy, use of mailing lists or newsletters, very active use of numerous social media channels, and large audience of followers)

Relating to accessibility, we verified the existence of any restrictions or the presence of multi-language sections (low level: platform with restrictions on the use and lack of multi-language sections; medium level: no restrictions on the use of the platform and lack of multi-language sections; and high level: no restrictions on the use of the platform and presence of multi-language sections).

For interactivity, the analysis focused on the presence of spaces for discussion or cocreation (low level: no pages produced/managed by users and no specific space dedicated to the co-creation of content; medium level: presence of pages produced/managed by users and no specific space dedicated to the co-creation of content; and high level: presence of pages produced/managed by users and availability of spaces dedicated to the co-creation of content).

Finally, an assessment criteria of the influence was the presence of news or evidence about the impact of the proposed actions, inside and outside the network of the subjects involved in the SP (low level: no evidence of external initiatives promoted and relative impact; 
medium level: evidence of initiatives carried out with/in favor of external stakeholders; and high level: evidence of initiatives carried out with/in favor of external stakeholders and assessment/definition of the related impacts).

Finally, in the third part of the study, with the aim of mitigating the intrinsic risks of action research, in particular the self-referentiality of the researchers evaluating a project in which they are directly involved, we investigated how the stakeholder engagement strategy of SoPHIA platform is perceived by the main stakeholders themselves, according to the four dimensions of investigation [17].

From the point of view of the research protocol, we first conducted an in-depth analysis of the text on the platform, as well as interviews with the actors involved in its maintenance. Afterwards, an online survey to explore the potential of the SoPHIA digital platform has been sent to all the partners of the project. The questionnaire aims at retrieving information on the users' perception of the DSP. In order to collect both quantitative and qualitative data on users' experience with the SoPHIA DSP, 4 Likert scale questions (using a scale of 1 to 7 ) and 4 open questions per each dimension are reported in the questionnaire.

The survey has been circulating among SoPHIA partners since the end of July 2021 and it has collected 11 answers from the 7 organizations that constitute the SoPHIA Consortium. The answers were anonymized, and all the data collected were treated in full compliance with the privacy regulation.

\section{Results}

As per the adopted research protocol, the results will be discussed concerning first (a) the participants and the contents of the online discourses in the DSPs, the so-called "institutional SPs", and then the "non-institutional SPs"; and (b) the evaluation of the four dimensions of SNE related to the previously identified DSPs, as well as of SoPHIA DSP. We will then conclude (c) with the results of the online survey on the stakeholder perception of SoPHIA DSP.

\subsection{Participant and Content of the Online Discourse in the Digital SPs}

\subsubsection{Institutional SPs}

The ten digital SPs examined in this paper have been financed by the EU (Table 1). As part of EU projects, SPs are implemented and maintained by consortiums that encompass:

- Institutions/technical bodies, and policymakers;

- Research/experts (universities, research centers);

- NGO associations;

- Professionals/practitioners;

- Enterprises/firms, especially small or medium enterprises (SME).

Table 1. Institutional digital SPs.

\begin{tabular}{ccc}
\hline Name & \multicolumn{1}{c}{ Description } & Status * \\
\hline $\begin{array}{c}\text { Innovators in Cultural } \\
\text { Heritage (ICH) }\end{array}$ & $\begin{array}{c}\text { EU funded platform launched in 2018 which } \\
\text { provides news and a showcase of innovative } \\
\text { projects, and working spaces to enhance } \\
\text { collaboration within its community }\end{array}$ & active \\
& $\begin{array}{c}\text { It is an instrument helping policy makers to } \\
\text { identify local strengths and opportunities } \\
\text { and benchmark their cities against similar } \\
\text { urban centres using both quantitative and }\end{array}$ & \\
Cultural and Creative & qualitative data. The platform offer a pool of \\
Cities Monitor & last edition: 2019 \\
& dimensions) over 190 cities. Dedicated & \\
& sections allow making comparisons, adding \\
data and mapping cultural places & \\
&
\end{tabular}


Table 1. Cont.

\begin{tabular}{|c|c|c|}
\hline Name & Description & Status * \\
\hline Cultural Base & $\begin{array}{l}\text { Social Platform funded by the European } \\
\text { Commission's Horizon } 2020 \text { programme } \\
\text { exploring the potential of culture as an area } \\
\text { of public policy. Its platform organizes } \\
\text { reflections and consultations based on a } \\
\text { review of relevant academic and policy } \\
\text { debates, a consultation with stakeholders } \\
\text { and a dialogue with non-academic } \\
\text { stakeholders }\end{array}$ & ended in 2017 \\
\hline HESIOD & $\begin{array}{l}\text { Platform aiming to identify, analyze, give } \\
\text { visibility and disseminate socially innovative } \\
\text { experiences in the field of cultural heritage }\end{array}$ & active \\
\hline REACH-Project & $\begin{array}{l}\text { Platform conceived as a space for meeting, } \\
\text { discussion and collaboration between } \\
\text { stakeholders within the field of culture and } \\
\mathrm{CH} \text { : professionals, academic experts, arts } \\
\text { practitioners, associations and interest } \\
\text { groups representative of non-professionals } \\
\text { and local societies, policy-makers }\end{array}$ & active \\
\hline
\end{tabular}

\begin{tabular}{ccc}
\hline $\begin{array}{c}\text { PLUGGY (Pluggable } \\
\text { Social Platform for }\end{array}$ & $\begin{array}{c}\text { Digital platform that features four open } \\
\text { access online applications that encourage its } \\
\text { users to create either AR or VR exhibitions; } \\
\text { self-guided audio tours; online collaborative } \\
\text { games and soundscapes }\end{array}$ & ended in 2019 \\
Ruritage & $\begin{array}{c}\text { Project that emphasizes the potential of } \\
\text { cultural and natural heritage to create and } \\
\text { enhance social capital, and therewith } \\
\text { facilitate social inclusion in the context of } \\
\text { rural regeneration }\end{array}$ & active \\
\hline Creative CH & $\begin{array}{c}\text { Project aims at making cities and regions } \\
\text { across Europe aware of the values of cultural } \\
\text { heritage, by sharing documents and } \\
\text { organizing initiatives to communicate and } \\
\text { promote cultural heritage for purposes such } \\
\text { as regional development, tourism and citizen } \\
\text { cultural participation }\end{array}$ & ended in 2014 \\
\hline ROCK & $\begin{array}{c}\text { Platform offers a repertoire of successful } \\
\text { heritage-led regeneration initiatives and } \\
\text { tools for heritage-led regeneration }\end{array}$ & active \\
\hline$\left.{ }^{*}\right)$ Status derived from the last home page/news page update.
\end{tabular}

(*) Status derived from the last home page/news page update.

The most significant distinctive elements of the digital SPs can be summarized as follows:

1. Sharing information on innovative projects to bridge the gap between research, market, and society (ICH) by identifying, analyzing, giving visibility, and disseminating socially innovative experiences in the field of cultural heritage (HESIOD).

2. Enhancing institutional awareness on strengths and opportunities and benchmark about $\mathrm{CH}$ initiatives (Cultural and Creative Cities Monitor), through sharing data and knowledge tools (recommendations, guidelines, and repertoires of best practices) to facilitate the replication of initiatives as well as their orientation to innovation goals.

3. Enhancing community participation. Innovation is often directly related to community participation in cultural heritage activities (HESIOD) or looking at citizens as "ambassadors of their cultural identity" and responsible for safeguarding and enriching the European cultural heritage landscape. 
4. Addressing problems related to conflicting/diverse/evolving concepts of $\mathrm{CH}$ for different people, groups, and nations "exploring questions of identity and for overcoming barriers to mutual understanding and tolerance" (REACH project) and giving specific attention to "how does a feeling of belonging to Europe relate to other important collective and political identities, such as national identity or indeed ethnic or minority identity" (Cultural base).

5. Widening/Reshaping the use of digital technology for the cultural heritage sector, focusing the attention on the increasing number of digital applications unlocking new forms of access, interpretation, social inclusion, and enhancing the visitor experience, while also increasing cultural consumption, attracting new audiences and improving revenues (REACH project).

\subsubsection{Non-Institutional SPs}

In line with the Faro Convention approach, which promotes the engagement of informal communities, this study goes beyond the perimeter of EU-funded projects. Hence, four non-institutional platforms were included in our study that are promoted by communities of stakeholders in the cultural field without the support of the EU (Table 2). All the non-institutional DSPs are promoted and implemented by associations. Their maintenance and improvement can be considered as an essential activity of every association. These digital SPs give a direct voice to affiliated associations and experts, and indirectly to the larger community engaged in activities promoted by the associations.

Table 2. Non-institutional digital SPs.

\begin{tabular}{|c|c|c|}
\hline Name & Description & Status * \\
\hline $\begin{array}{l}\text { Network of European } \\
\text { Museum } \\
\text { Organizations } \\
\text { (NEMO) }\end{array}$ & $\begin{array}{l}\text { Independent network of national museum organizations } \\
\text { that represent the museum community of the member } \\
\text { states of the Council of Europe, aiming to turn museums } \\
\text { to an integral part of European life, by promoting their } \\
\text { work and value to policy makers and by providing their } \\
\text { associated museums with information, networking and } \\
\text { opportunities for collaboration. The NEMO SP provides } \\
\text { tools and information for advocacy, networking, } \\
\text { funding and training }\end{array}$ & active \\
\hline $\begin{array}{l}\text { Cultural Action } \\
\text { Europe (CAE) }\end{array}$ & $\begin{array}{l}\text { Based in Brussels, it is the largest interdisciplinary } \\
\text { forum for the non-governmental cultural sector in } \\
\text { Europe. With more than } 145 \text { member organizations } \\
\text { from both Western and Eastern Europe, CAE represents } \\
\text { the interests of artists and cultural workers and acts as a } \\
\text { mediator vis-a-vis the European political and } \\
\text { administrative bodies. Its Social Platform provides } \\
\text { toolkits and information on advocacy, knowledge, } \\
\text { campaigns, projects and initiatives. }\end{array}$ & active \\
\hline
\end{tabular}


Table 2. Cont.

\begin{tabular}{|c|c|c|}
\hline Name & Description & Status * \\
\hline Europa Nostra (EN) & $\begin{array}{l}\text { Founded in } 1963 \text { in Paris, it is a representative heritage } \\
\text { organisation in Europe with members from over } 40 \\
\text { countries, incorporating } 239 \text { heritage associations and } \\
\text { foundations with a combined membership of more than } \\
5 \text { million people, } 111 \text { governmental bodies, local } \\
\text { authorities, universities and corporations and over } 1000 \\
\text { Individual Members. In addition to providing } \\
\text { information on campaigns, awards and other activities } \\
\text { promoted by EN, the social platform now encompasses } \\
\text { a "digital agora", provided as a reaction to the } \\
\text { consequences of the Covid pandemic, where it's } \\
\text { possible to share and promote digital best practices } \\
\text { related to culture and cultural heritage from across } \\
\text { Europe and the world. Through this platform, citizens, } \\
\text { civil society organisations and so many cultural } \\
\text { (heritage) operators can connect, interact and learn from } \\
\text { one another across various types of borders and barriers }\end{array}$ & active \\
\hline Digicult & $\begin{array}{l}\text { One of the main international platforms investigating } \\
\text { the impact of technologies and sciences on art, design } \\
\text { and contemporary culture. Founded in 2005, it is } \\
\text { formed by a wide network of curators, critics and } \\
\text { theorists, teachers and researchers. Digicult publishes } \\
\text { news, essays, interviews, books and its own journal. It } \\
\text { organizes exhibitions, performances, workshops and } \\
\text { lectures, and it offers tools for digital publishing and } \\
\text { communication strategies for art and culture }\end{array}$ & active \\
\hline
\end{tabular}

For non-institutional SPs, the common features identified by our study can be summarized as follows:

1. Culture is a practice rather than a resource (CAE), plural and exploratory; cultural structures are democratizing, inclusive, and polyphonic spaces for critical dialogue; a different consideration of Culture (and $\mathrm{CH}$ ) is the basis for re-defining missions, goals, and activities beyond the usual tracks.

2. $\mathrm{CH}$ is a field where not-for-profit and for-profit initiatives can be combined in innovative ways. The not-for-profit sector is seen as an essential agent of innovation: "the not-for-profit sector is a fertile ground for innovation because of a lower burden in terms of profit generation and shareholder's value" (NEMO). The social debate also highlights that it is necessary to advocate for more involvement of private investors and businesses in developing culture and heritage to unleash the economic potential of the cultural and creative sectors (EN).

3. Digital space can be used as an empowering tool. Open and common-based digital spaces can help mobilize collective action at an unprecedented scale: mobilizing large communities, sharing knowledge to create "collective intelligence", and spreading power (Digicult).

4. Heritage is at risk. The rising attention towards $\mathrm{CH}$ as an open and evolutionary system, deeply related to "experiences, memories, feelings, and emotions" [36] (p. 6), should not obscure how difficult it is to preserve heritage-as-a-thing from destruction, damages, and deterioration.

\subsection{SNE Analysis}

The proposed analysis highlights a substantial homogeneity of results between DSPs in the two different subgroups, named institutional and non-institutional SPs (Table 3). 
However, we cannot ignore the fact that the highest performance was assigned to noninstitutional platforms.

Table 3. SNE analysis.

\begin{tabular}{|c|c|c|c|c|}
\hline \multirow{2}{*}{ Name } & \multicolumn{4}{|c|}{ SNE Dimensions } \\
\hline & Diffusion & Accessibility & Interactivity & Influence \\
\hline \multicolumn{5}{|c|}{ Institutional digital SPs } \\
\hline $\begin{array}{c}\text { Innovators in Cultural } \\
\text { Heritage (ICH) }\end{array}$ & Low & Low & Medium & Low \\
\hline $\begin{array}{l}\text { Cultural and Creative } \\
\text { Cities Monitor }\end{array}$ & Medium & Medium & Low & High \\
\hline Cultural Base & Low & High & Low & Low \\
\hline HESIOD & Low & Medium & Low & Low \\
\hline REACH-Project & Medium & High & Low & Low \\
\hline PLUGGY & Medium & Medium & Low & Medium \\
\hline Ruritage & High & Medium & Low & Medium \\
\hline Creative $\mathrm{CH}$ & Low & Medium & Low & Low \\
\hline ROCK & High & Medium & Medium & Medium \\
\hline \multicolumn{5}{|c|}{ Non-Institutional digital SPs } \\
\hline $\begin{array}{l}\text { Network of European } \\
\text { Museum Organizations } \\
\text { (NEMO) }\end{array}$ & High & Medium & Low & High \\
\hline $\begin{array}{l}\text { Cultural Action Europe } \\
\text { (CAE) }\end{array}$ & High & Medium & Low & Medium \\
\hline Europa Nostra (EN) & High & High & Medium & High \\
\hline Digicult & High & High & Low & Low \\
\hline \multicolumn{5}{|c|}{ Single case study } \\
\hline SoPHIA & High & Medium & High & High \\
\hline
\end{tabular}

Among the DSPs reported in this paper, SoPHIA stands out for the crucial role played by the project's stakeholders within the platform. The SNE analysis confirms that the SoPHIA DSP has been designed and implemented to ensure the active participation of its users.

Despite the declared intent of the institutional DSPs to incentivize the diffusion of the content to other individual stakeholders that may not have been in the original audience, as well as sharing information on innovative projects, the results appear fragmented and, in some cases, rather unsatisfying (ICH, Cultural base, HESIOD, and Creative $\mathrm{CH}$ ). On the contrary, the level of diffusion in the non-institutional platforms is very high, in line with the declared intentions, due to a constant commitment to online communication (newsletters and social media), as well as to the online promotion of events organized in person.

In line with the best practices emerging from the analysis of non-institutional DSPs, the contents of SoPHIA are made fully available for those who have joined the shared workspace. Initially, the SoPHIA DSP was composed by SoPHIA's partners and the stakeholders that were identified at the beginning of the project. Nevertheless, the DSP expanded throughout the project through two open calls (June 2020 and February 2021) to enroll new members, including spontaneous applications of academics, practitioners, and policymakers interested in being part of the SoPHIA community.

Although the discussion and the research process are available only to those who have access to the DSP and have joined the workspace(s), the main outcomes derived from the 
interaction between (and among) the Consortium and SoPHIA' stakeholders, resources (documents other than those produced by the project), useful links, and the archive (all key documents and material produced by SoPHIA) are reported in the project website too, in order to make them available to the general public. In fact, the SoPHIA website and the online collaborative platform are digital tools supporting the overarching concept and intention of the social platform of gathering a broad and diverse community of people interested in impact assessment of cultural interventions.

Much more encouraging data emerges from the analysis of the accessibility of DSPs, with the sole exception of the platform "Innovators in Cultural Heritage (ICH)", all platforms do not have restrictions on the display/use of the proposed contents, and, in some cases, they also offer multi-language spaces (Cultural Base, REACH-Project, Europa Nostra, and Digicult).

SoPHIA presents two different levels of accessibility, in line with its institutional purposes. On the one hand, all the main outcomes derived from the interaction between (and among) the Consortium and SoPHIA' stakeholders, resources (documents other than those produced by the project), useful links, and the archive (all key documents and material produced by SoPHIA) are available to the general public on the project's website. On the other hand, only professionals having received clearance by the Consortium can access the restricted platform by using their credentials.

The most prominent challenges are related to the theme of interactivity. One of the milestones of the institutional DSPs strategy is precisely that of enhancing community participation. Our analysis, however, shows that this purpose is neglected, as we highlight the lack of information/data sharing spaces and, above all, of co-creation by users. The only exceptions in this sense come from "Innovators in Cultural Heritage", which provides a working space (even if the interaction between users is very scarce), and "ROCK", where, although there is no dedicated forum space, there is at least the possibility of commenting on the proposed initiatives. The same deficit also emerges in the analysis of non-institutional DSPs, of which only "Europa Nostra" proposes a "digital agora" for users (albeit not particularly frequented by the targeted community) as well as the possibility of voting on the projects proposed to manifest one's preference.

Therefore, if, on the one hand, it is recognized that the digital space can be used as an empowering tool and that the opportunity given by digital technology to foster social inclusion, due to new forms of access to content, is generally appreciated. On the other hand, DSPs are "showcases" of static, non-interactive content, certainly not designed to encourage the co-creation of value among stakeholders.

SoPHIA completely deviates from these experiences, precisely in response to the past criticalities that emerged from the comparative analysis of DSPs. To enhance community participation and boost interactivity, the SoPHIA DSP provides different online working spaces for stakeholders to participate in the debate on relevant topics related to the project. Moreover, stakeholders are encouraged to propose new topics to be discussed, share their expertise, and post new contents to enrich the debates on the platform and to (co-) produce additional content. By connecting to the SoPHIA DSP, stakeholders can access all the tools provided, including agendas, Wikis, chats, web conferencing, and shared documents to collectively debate information, paper drafts, and issues related to the scientific outputs of the project with the rest of the SoPHIA community. It should be noted that the accessibility level was evaluated as medium, because there are no multi-language sections of the DSP.

Another relevant, and in some ways surprising, data comes from the analysis dimension defined as influence where the best results are the prerogative of non-institutional platforms. This is certainly in line with the declared aims of these informal communities aimed at raising attention towards $\mathrm{CH}$ as an open and evolutionary system, as well as at creating an integrated space between not-for-profit and for-profit initiatives. On the contrary, there are widespread difficulties experienced by the institutional platforms in proposing their own requests, finding their own "voice" at the national and European institutions that finance the initiatives, thus creating a logical short circuit. There are certainly 
exceptions to some extent (Cultural and Creative Cities Monitor, PLUGGY, Ruritage, and ROCK) which, however, do not seem to solve the difficulties described above.

Finally, when applied to the SoPHIA DSP, the influence dimension can be analyzed from two different perspectives: the ability of SoPHIA to persuade others to pass on, distribute, or interact with their content and message [34], and the importance of a mutual exchange among the platform's users.

On one hand, SoPHIA's partners are key actors in leading the discussion and the flow of information by revising and commenting on the different interactions among users, hence, enabling a positive co-creation among the different actors. In particular, stakeholders contribute through their active engagement in the discussions on the research findings and by supporting the dissemination of the project's outputs.

On the other hand, a mutual exchange of feedback and opinions on relevant topics discussed on the platform is encouraged. As a matter of fact, by including the feedback of a diverse community of professionals, the SoPHIA DSP ensures a multi-perspective and inclusive approach in analyzing the issues addressed on the platform and, at the same time, it promotes knowledge sharing.

From the comparative analysis produced it emerges that among the DSPs reported in this paper, SoPHIA stands out for the crucial role played by the project's stakeholders within the platform. The SNE analysis confirms that the SoPHIA DSP has been designed and implemented to ensure the active participation of its users.

The project' DSP, alongside the physical and virtual meetings and events, is the tool to facilitate the work between (and among) Consortium partners and stakeholders. It is intended as the online meeting point, where all relevant project's outputs are regularly uploaded, discussed, and analyzed. The SoPHIA DSP proposes a participative model for the research process, by sharing and commenting on the scientific outcomes with all the actors interested in the field. Based on the synergy among these different actors, the SP gathers different perspectives to formulate both recommendations and an action plan for future European policies. This also means building a consensus on future needs and supporting the EU in developing an innovative and focused research agenda on cultural heritage and the quality of interventions in heritage sites in Europe.

\subsection{Stakeholders' Perception of SoPHIA DSP}

As mentioned in the methodological part of our work, the research group-directly involved both in the design of SoPHIA DSP and in its evaluation-decided to compare the results produced and discussed in the previous paragraph with the perception expressed by the stakeholders on the same dimensions of analysis.

The level of diffusion is generally considered medium-high by the stakeholders (Figure 1), in line with the results of the evaluation presented above. In this sense, there is a coherence between the design and management effort of the digital platform and the user experience.

The qualitative responses also confirmed some positive aspects, such as

"SDP allows to share content and engage the right targeted audience"; "SoPHIA DSP allow to share content and engage the target audience".

Other answers offer interesting ideas for improvement relating to the methods of conveying content, especially regarding social media:

"I think the SoPHIA DSP's content diffusion may be improved by adding an Instagram account. Museums, for example, have sustained engagement with followers primarily through Instagram. Perhaps TikTok can also be used to engage the younger audience".

Some stakeholders have criticized the organization of the platform, but also proposing a possible area for improvement:

"Rather complicated structure [...] is not very self-explanatory"; "I would need a guided selection system". 


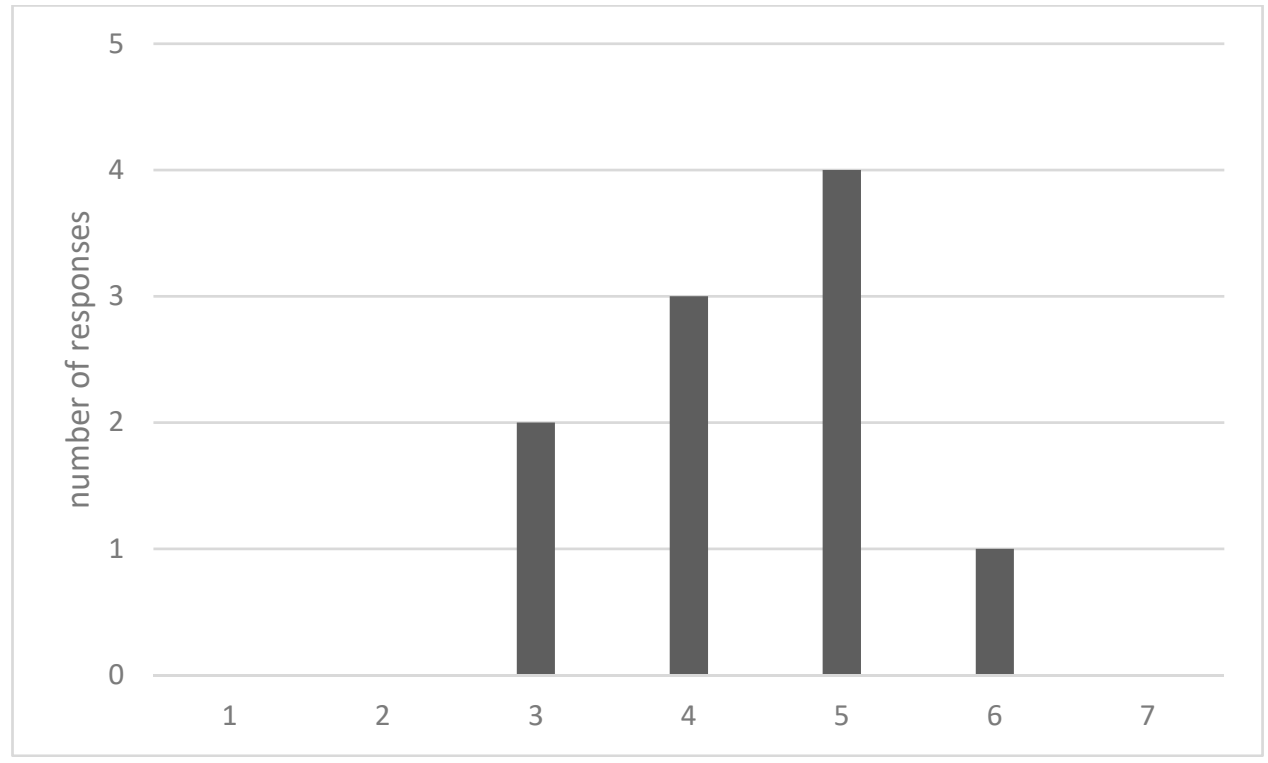

Figure 1. Diffusion of SoPHIA.

The accessibility analysis dimension (Figure 2) also confirms the good results highlighted by the DSPs, both the institutional and non-institutional ones. In this sense, the average obtained from the perception level, equal to 4.7 , is not surprising. On the contrary, a wide distribution of the results emerges, a trend even more amplified in the subsequent survey dimensions.

\section{5}

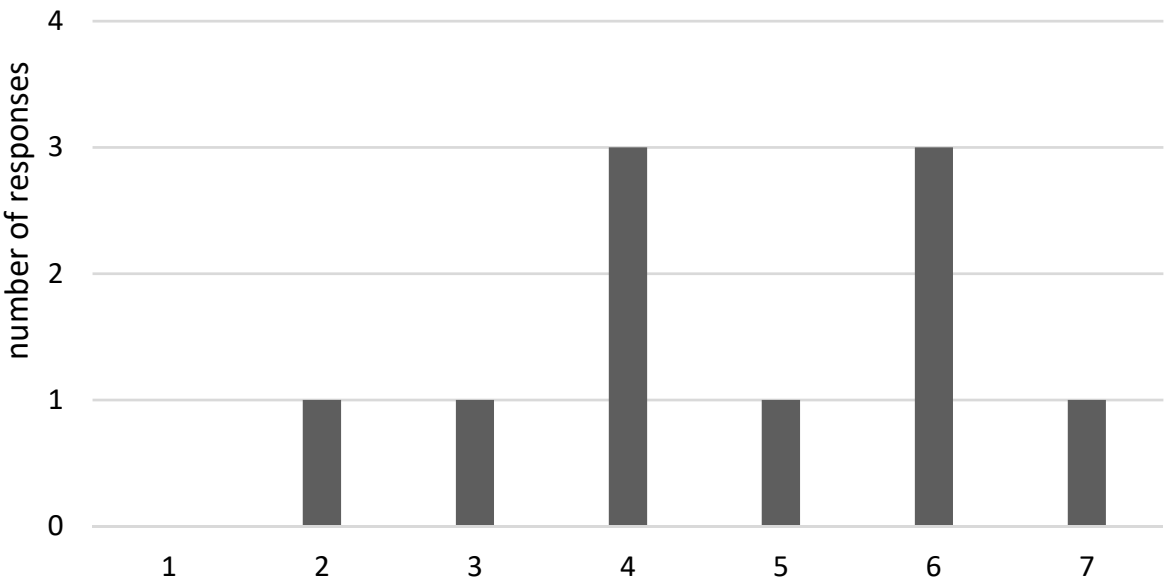

Figure 2. Accessibility of SoPHIA.

While accessibility for project partners is absolute, several items highlight the possible limitations/difficulties encountered by potential external users:

"The needed password is for sure necessary, but also a barrier"; "I am not sure that stakeholders other than the partners regularly access the content of the DSP".

Particularly appreciable is the attention due not only to (potential) technological barriers, but also to linguistic or skills/experience in accessing the documentation/material proposed:

"[... ] SoPHIA's material can be intimidating even for professionals since it is very complex. A more concerted effort should be made to use language and simplified material, to reach the public and community groups". 
The results relating to interactivity are particularly surprising, as seen in Figure 3; the perceptions of the stakeholders are very contradictory, despite the numerous spaces and tools made available to them to encourage their interactivity level and co-creation of contents.

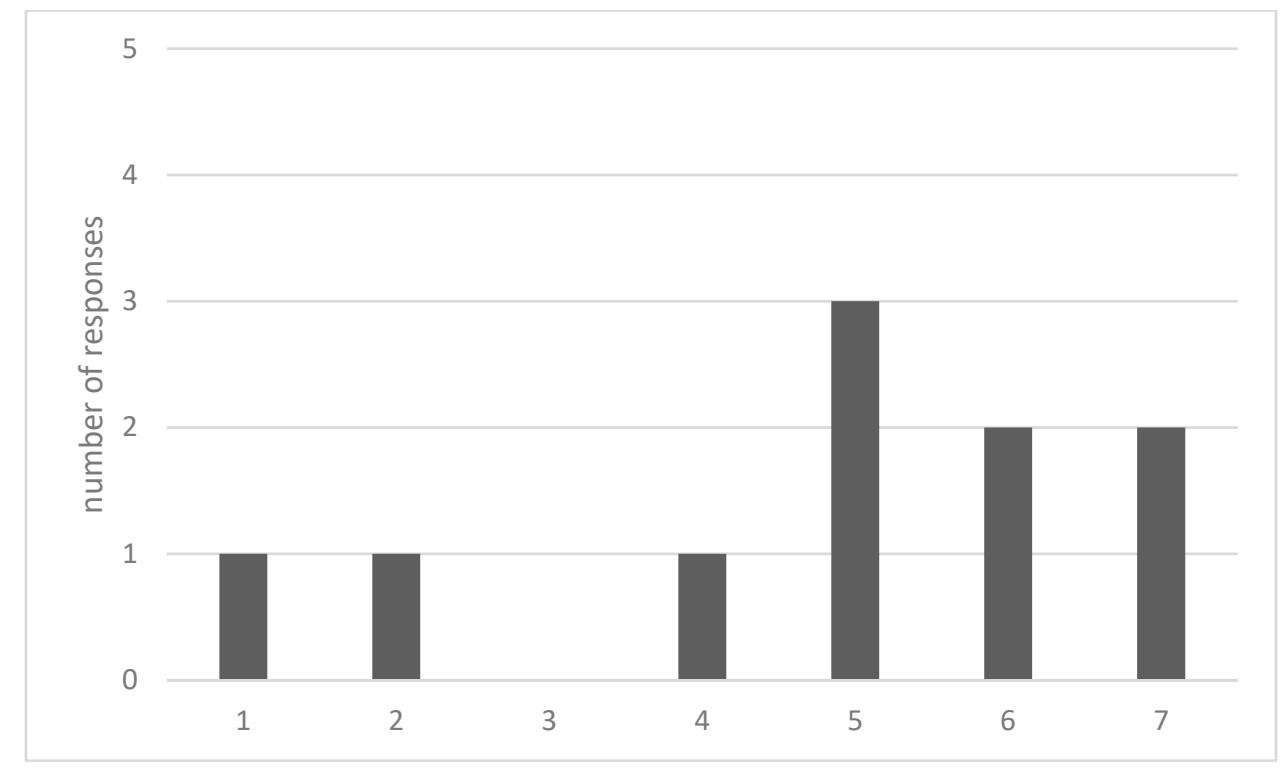

Figure 3. Interactivity of SoPHIA.

The analysis of the qualitative responses partially manages to explain this situation as the subjects who rated the level of interaction of SoPHIA very negatively expressed themselves exclusively on their own direct experience and not on the technological potential of the platform:

"Until now we only had few situations using the possibilities for interaction. There are potentially good functions like chat, common working on a document, calendar, etc.".

On the contrary, some of the subjects that have expressed higher evaluations have assessed the technological potential of the platform, while highlighting the low current use:

"While there is an option of creating new content online for the consortium and stakeholders, I have the feeling that the option has not really been exploited to its full potential"; "Potentially, the level of interaction could be very high. Actually, it remains very static".

Finally, beyond the very wide distribution of the responses related to the influence that SoPHIA exerts through the proposition of its work (Figure 4), it is interesting to note how almost all respondents to the survey understood the concept of influence as addressed only within the community to which they belong to without considering the concept of external influence, towards institutional and non-institutional subjects.

The positive results that emerge from the survey are related to the ability of the digital platform to encourage cooperation between stakeholders or are justified by the inability to convey the message outside the community due to the complexity of the issues addressed by the project itself:

"SDP fosters the cooperation among stakeholders"; "[ ... ] I think we should be realistic and respect that the theme-impact assessment in cultural heritage—cannot be expected to catch the eye of a big crowd. It is for specialists".

Moreover, negative perceptions derive from the inability to dedicate adequate resources to the project or from the inability to transform successful face-to-face initiatives into equally engaging and impactful online activities:

"I don't think we had enough time in the project for this [ ... ]"; "I feel the networking platform is not working to its full potential. While the interaction and participation of stakeholders were substantial during the stakeholders' conference in April 2021, it has been scarce for the rest of the time". 


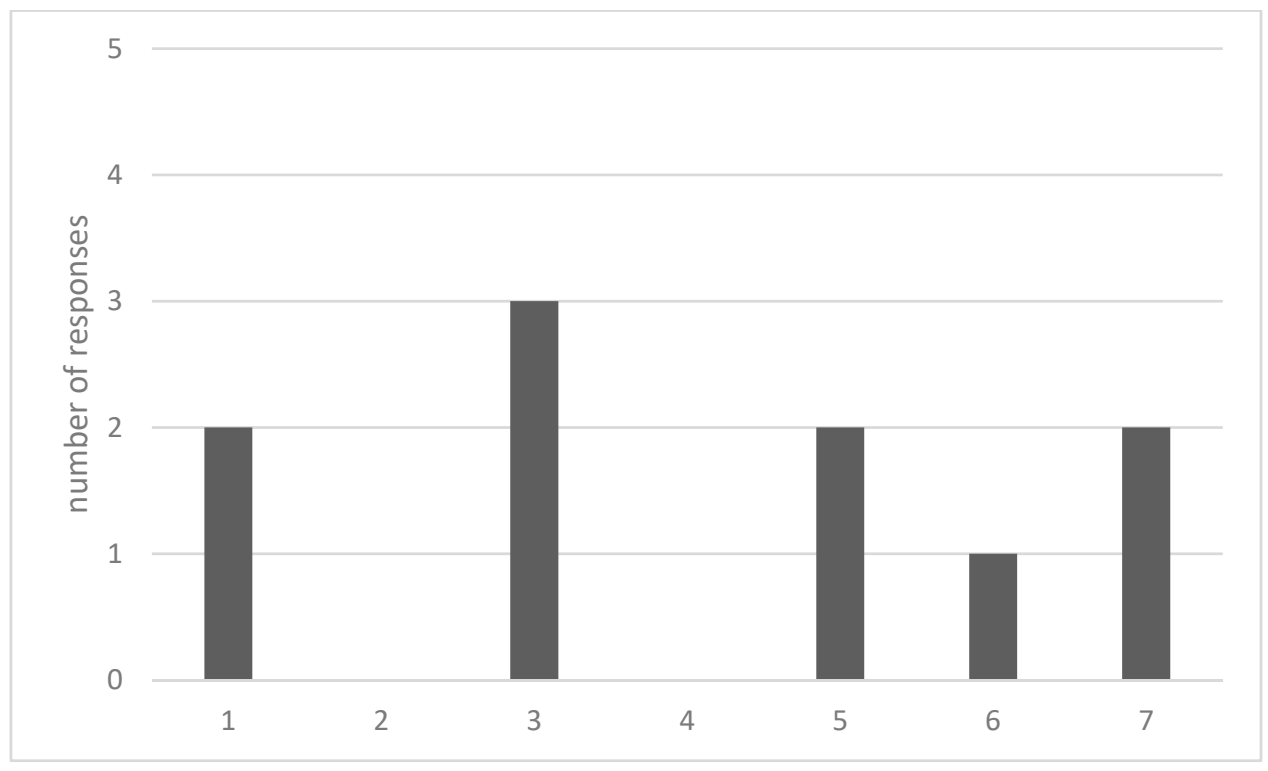

Figure 4. Influence of SoPHIA.

\section{Conclusions and Further Research}

Our research was aimed at understanding whether digital social platforms (DSPs) in the specific context of cultural heritage are effective tools to pursue stakeholders' network engagement strategies, boost participation, and give space to collaboration to wider audiences and groups of stakeholders. This piece of research is rooted in the most recent theoretical streams that link broader participation and engagement in cultural heritage management to improved awareness of social problems, more effective practices, wider social inclusion, and well-being. We complement these streams by considering the recent theoretical debate on digital technologies and the digital social platforms as instrumental to the virtuous process of engagement. The digital social platforms provide engagement contexts that should sustain and reinforce stakeholders' participation. Following these assumptions, this paper builds on the framework that identifies four dimensions of stakeholders' network engagement and tests the framework on several institutional and non-institutional DSPs in the cultural heritage management sector.

Our results partially support the research question, by providing some good results, as well as some critical issues in terms of the theoretical framework that focuses on diffusion, accessibility, interactivity, and influence. In general, both institutional and non-institutional SPs are broadly diffused, displaying only a minor part of the content with restricted access. This grants content to actors that were not included in the original targeted audience [30]. Moreover, accessibility varies a lot from one SP to another. In general, institutional SPs reach out to a wider number of stakeholders [31,32]. At odds, the interactivity of noninstitutional SPs is higher as in these cases the audience was more active in exchanging in content co-production [33]. Finally, it was not easy to assess the SPs' influence due to a lack of key indicators.

The DSPs examined in our review gave space to alternative economic approaches to sustainable development based on a cross contamination of for-profit and non-profit activities, and to different aspects of social innovations to integrate the greater public, to increase capability production, and to foster the integration of minority groups (Sophia D1.1, pp. 54). Moreover, they can give better evidence to the potential side-effects of cultural interventions to be considered in impact assessment, such as over-tourism, gentrification, land rent increase, the commodification of artistic production, and environmental impact (cultural sites can also be part of vulnerable landscapes and natural areas). The case of SoPHIA DSP stands out in promoting knowledge sharing among different actors involved in a specific cultural project, as well as among actors with similar competencies involved in 
different cultural projects. Evidence on the actual translation of such shared knowledge into action is still very limited and is not captured by the SNE framework.

These results allow some critical reflections on the theoretical framework that help assessing the level of SNE. When it is applied to a specific context, such as the cultural heritage sector, it appears to partially capture the implication of DSPs for stakeholders' engagement and its outcomes. On one side, the four dimensions reflect the livelihood and the potential to reach out to specific communities. Nevertheless, they do not capture the ability to convey the online discourse onto effective outcomes and innovation. In fact, whereas the analysis of the DSPs, and the SoPHIA DSP in particular, is effective in assessing the collaboration of the project community, some incremental effort should be devoted to the understanding of the ability to reach out to external policymakers and relevant actors. Therefore, in line with the philosophical debate about virtual reality and actual reality [11], we propose that additional research focus on how the knowledge shared and produced in a virtual environment is translated into the actual course of action. We suggest that additional dimensions enrich the SNE framework to capture the outcomes of the DSPs. In terms of production of knowledge, the dimensions related to the roles of the DSPs participants in enlarging the platform, managing the network dynamics, and capturing the relevant information and knowledge deserve better scrutiny in future research.

Moreover, the network dynamics that connect a focal DSP to others in the $\mathrm{CH}$ field are loosely investigated. Our results show that the usage of DSPs in the $\mathrm{CH}$ field is promoted and sustained also at the institutional level, as effective tools to foster participation of wide communities. Nevertheless, participants in several DSPs can overlap, as one actor can be part of several communities in particular $\mathrm{CH}$ domains. The SNE framework, though, is not fully adequate to capture cross-DSPs information flows and network externalities. Therefore, we propose that additional dimensions are tested to capture these effects.

Our results offer valuable insights to practitioners, as $\mathrm{CH}$ managers should devote more attention to how members of the communities of practice connect and participate in the $\mathrm{CH}$ debate, especially in terms of influence. Managers of $\mathrm{CH}$ projects should be aware that the information flows and the knowledge sharing processes within the DSPs should be constantly reinforced and kept lively to sustain the stakeholders' perceptions of the DSP utility. It would be wise to appoint a DSP manager to constantly monitor the level of involvement in the DSP, and to elicit the debate and knowledge sharing. Additionally, an inter-organizational perspective could lead to foster some connections between different DSPs.

To conclude, this research provided a snapshot of the current state of the literature and practices on DSPs pointing out directions for future research. Our results stress that, in the cultural heritage sector, the framework based on the four dimensions should be further developed in two directions. First, further research is needed to add a longitudinal perspective to the framework, which appears to be rather static and not to grasp the dynamics of network evolution and how the discourses develop in different communities. In particular, for institutional DSPs it would be necessary to understand whether, and to what extent, the duration of these digital communities is intrinsically linked to the duration of the projects. Second, additional studies would help refining and tailoring all the variables, which appears to be only roughly adequate. More insights on the participatory mechanisms in DSPs would allow a better understanding on the impact of the online discourses in folding the cultural agenda and the cultural management practices.

We are aware of the limitation of our study. First, we did not have access to primary data for the DSPs other than SoPHIA's. Moreover, being part of the SoPHIA consortium, while it gave us privileged access to primary data, it could bear some potential bias. We believe that we have kept this risk to a minimum, by applying rigorous methods of research. Nevertheless, future research could gather richer databases. Moreover, we focused on the $\mathrm{CH}$ field, thus limiting our conclusions to specific $\mathrm{CH}$ DSPs. We do believe that some of our thoughts do apply to other fields, in which participation is encouraged, but our data 
do not allow for further generalization of our results. We hope that our contribution is taken as a stimulus for further research both in the $\mathrm{CH}$ field and other similar fields.

Author Contributions: Conceptualization, M.B., F.C., P.D., L.M., M.M. and F.M.; methodology, F.C. and L.M.; software, F.M.; validation, M.B., F.C., P.D., L.M., M.M. and F.M.; formal analysis, M.B., F.C., L.M.; data curation, M.B., F.C., F.M.; writing-original draft preparation, M.B., F.C., L.M., F.M.; writing-review and editing, F.C., L.M.; supervision, P.D., L.M., M.M. All authors have read and agreed to the published version of the manuscript.

Funding: This research was funded by the Program of the European Union for Research and Innovation Horizon 2020 (GA nº870954).

Institutional Review Board Statement: Ethical review and approval were waived for this study, due to the overarching compliance with the EU funded program Horizon 2020, under which the SoPHIA project is funded and monitored.

Informed Consent Statement: Informed consent was obtained from all subjects involved in the study.

Conflicts of Interest: The authors declare no conflict of interest.

\section{References}

1. Wilkin, C.L.; Campbell, J.; Moore, S.; Simpson, J. Creating value in online communities through governance and stakeholder engagement. Int. J. Account. Inf. Syst. 2018, 30, 56-68. [CrossRef]

2. Barrett, M.; Oborn, E.; Orlikowski, W. Creating value in online communities: The sociomaterial configuring of strategy, platform, and stakeholder engagement. Inf. Syst. Res. 2016, 27, 704-723. [CrossRef]

3. Howe, J. The rise of crowdsourcing. Wired Mag. 2006, 14, 1-4.

4. Liu, C.H.S. Examining social capital, organizational learning and knowledge transfer in cultural and creative industries of practice. Tour. Manag. 2018, 64, 258-270. [CrossRef]

5. Tomka, G. Reconceptualizing cultural participation in Europe: Grey literature review. Cult. Trends 2013, 22, 259-264. [CrossRef]

6. Demartini, P.; Marchegiani, L.; Marchiori, M.; Ceschel, F. The Rhetoric of Participation in the Governance of Culture: The Case of European Capitals of Culture. In Proceedings of the 2021 European Academy of Management Conference (EURAM), Winterthur, Switzerland, 16-18 June 2021; ISSN 2466-7498. ISBN 978-2-9602195-3-1.

7. Biondi, L.; Demartini, P.; Marchegiani, L.; Marchiori, M.; Piber, M. Understanding orchestrated participatory cultural initiatives: Mapping the dynamics of governance and participation. Cities 2020, 96, 102459. [CrossRef]

8. Bassler, A.; Brasier, K.; Fogel, N.; Taverno, R. Developing Effective Citizen Engagement: A How-to Guide for Community Leaders; Center for Rural Pennsylvania: Harrisburg, PA, USA, 2008.

9. Gaventa, J.; Barrett, G. So what difference does it make? Mapping the outcomes of citizen engagement. IDS Work. Pap. 2010, 2010, 01-72. [CrossRef]

10. Reddel, T.; Woolcock, G. From consultation to participatory governance? A critical review of citizen engagement strategies in Queensland. Aust. J. Public Adm. 2004, 63, 75-87. [CrossRef]

11. Driessen, A. The Universe as a Computer Game, from Virtual to Actual Reality. Sci. Fides 2018, 6, 31-52. [CrossRef]

12. Rowley, T.J. Moving beyond dyadic ties: A network theory of stakeholder influences. Acad. Manag. Rev. 1997, 22, 887-910. [CrossRef]

13. Alexander, M.J.; Jaakkola, E.; Hollebeek, L.D. Zooming out: Actor engagement beyond the dyadic. J. Serv. Management 2018, 29, 333-351. [CrossRef]

14. Harmeling, C.M.; Moffett, J.W.; Arnold, M.J.; Carlson, B.D. Toward a theory of customer engagement marketing. J. Acad. Mark. Sci. 2017, 45, 312-335. [CrossRef]

15. Venkatesan, R. Executing on a customer engagement strategy. J. Acad. Mark. Sci. 2017, 45, 289-293. [CrossRef]

16. Nieborg, D.B.; Poell, T. The platformization of cultural production: Theorizing the contingent cultural commodity. New Media Soc. 2018, 20, 4275-4429. [CrossRef]

17. Okazaki, S.; Plangger, K.; Roulet, T.; Menéndez, H.D. Assessing stakeholder network engagement. Eur. J. Mark. 2020, 55, 1359-1384. [CrossRef]

18. Ambrosino, M.A.; Andriessen, J.; Annunziata, V.; De Santo, M.; Luciano, C.; Pardijs, M.; Pirozzi, D.; Santangelo, G. Protection and preservation of campania cultural heritage engaging local communities via the use of open data. In Proceedings of the 19th Annual International Conference on Digital Government Research: Governance in the Data Age, Delft, The Netherlands, 30 May-1 June 2018; pp. 1-8.

19. Lim, V.; Frangakis, N.; Tanco, L.M.; Picinali, L. PLUGGY: A pluggable social platform for cultural heritage awareness and participation. In Advances in Digital Cultural Heritage; Springer: Cham, Switzerland, 2018.

20. Cordasco, G.; De Donato, R.; Malandrino, D.; Palmieri, G.; Petta, A.; Pirozzi, D.; Santangelo, G.; Scarano, V.; Serra, L.; Spagnuolo, C. Engaging citizens with a social platform for open data. In Proceedings of the 18th Annual International Conference on Digital Government Research, New York, NY, USA, 7-9 June 2017; pp. 242-249. 
21. Olivieri, A.C.; Schegg, R.; Sokhn, M. Cityzen: A social platform for cultural heritage focused tourism. In Proceedings of the 8th International Conference on Management of Digital EcoSystems, Biarritz, France, 1-4 November 2016; pp. $129-136$.

22. Eisenhardt, K.M. Building theories from case study research. Acad. Manag. Rev. 1989, 14, 532-550. [CrossRef]

23. Bakhshi, H.; Throsby, D. New technologies in cultural institutions: Theory, evidence and policy implications. Int. J. Cult. Policy 2012, 18, 205-222. [CrossRef]

24. Liang, S.; Schuckert, M.; Law, R.; Masiero, L. The relevance of mobile tourism and information technology: An analysis of recent trends and future research directions. J. Travel Tour. Mark. 2017, 34, 732-748. [CrossRef]

25. Cameron, F.; Kenderdine, S. Theorizing Digital Cultural Heritage: A Critical Discourse; MIT Press: Cambridge, MA, USA, 2007.

26. Giaccardi, E. (Ed.) Heritage and Social Media: Understanding Heritage in a Participatory Culture; Routledge: Abingdon-on-Thames, UK, 2012.

27. Russo, A.; Watkins, J.; Kelly, L.; Chan, S. Social media and cultural interactive experiences in museums. Nordisk Museologi 2007, 1, 19. [CrossRef]

28. Svendsen, A.C.; Laberge, M. Convening stakeholder networks. J. Corp. Citizsh. 2005, 19, 1-18. [CrossRef]

29. Greenwood, M. Stakeholder engagement: Beyond the myth of corporate responsibility. J. Bus. Ethics 2007, 74, 315-327. [CrossRef]

30. Porter, J.E. Recovering delivery for digital rhetoric. Comput. Compos. 2009, 26, 207-224. [CrossRef]

31. Scott, S.G.; Lane, V.R. A stakeholder approach to organizational identity. Acad. Manag. Rev. 2000, 25, 43-62. [CrossRef]

32. Slatin, J.M. Becoming an accessibility researcher: A memoir. In Technology and English Studies; Routledge: Abingdon-on-Thames, UK, 2020; pp. 143-162.

33. Neville, B.A.; Menguc, B. Stakeholder multiplicity: Toward an understanding of the interactions between stakeholders. J. Bus. Ethics 2006, 66, 377-391. [CrossRef]

34. Frooman, J. Stakeholder influence strategies. Acad. Manag. Rev. 1999, 24, 191-205. [CrossRef]

35. Yin, R.K. Case Study: Design and Methods; Sage Publications: Newbury Park, CA, USA, 1994.

36. Van Knippenberg, K. Towards an evolutionary heritage approach: Fostering community-heritage engagement. In Proceedings of the 13th AESOP Young Academics Conference, Darmstadt, Germany, 2-5 April 2019. 